\title{
ENFERMAGEM COMPREENDIDA COMO VOCAÇÃO E SUA RELAÇÃO COM AS ATITUDES DOS ENFERMEIROS FRENTE ÀS CONDIÇÕES DE TRABALHO ${ }^{1}$
}

Rosa Maria Rodrigues ${ }^{2}$

Rodrigues RM. Enfermagem compreendida como vocação e sua relação com as atitudes dos enfermeiros frente às condições de trabalho. Rev Latino-am Enfermagem 2001 novembro-dezembro; 9(6):76-82.

A proposta é refletir sobre a enfermagem enquanto trabalho, afastando sua concepção amplamente aceita que a identifica a uma atividade de ajuda, sendo que tal concepção poderia ser fator dificultante para o enfrentamento e transformação das condições de trabalho. Tenta situar na história o contexto em que é elaborado o modelo vocacional/religioso e identificar nas falas de alunos do primeiro e quarto ano de um curso de Graduação em Enfermagem as manifestações daquela concepção, apontando para a necessidade da atividade docente ser permeada pela concepção da enfermagem/trabalho.

DESCRITORES: enfermagem, trabalho

\section{NURSING UNDERSTOOD AS A VOCATION AND ITS RELATIONS TO NURSES' ATTITUDES TOWARDS WORK CONDITIONS}

This study aimed at reflecting about nursing as job by disconsidering the widely accepted conception that identifies it as an assistance activity for that conception might hinder actions towards coping with and changing work conditions. The study attempted to place in history the context in which the vocational/religious model was elaborated as well as to identify the manifestations of that conception in the discourse of Nursing freshmen and seniors, pointing out the fact that the teaching activity must be permeated by the conception of nursing/work.

KEY WORDS: nursing, work

\section{ENFERMERÍA COMPRENDIDA COMO VOCACIÓN Y SU RELACIÓN CON LAS ACTITUDES DE LOS ENFERMEROS FRENTE A LAS CONDICIONES DE TRABAJO}

La propuesta es reflexionar sobre la enfermería como trabajo, alejando su concepción ampliamente aceptada. que la identifica como una actividad de ayuda, siendo que tal concepción podría ser un factor que dificulta el enfrentamiento y la transformación de las condiciones de trabajo. Él trabajo intenta situar en la historia el contexto en que es elaborado el modelo vocacional/religioso e identificar en los discursos de los alumnos de pregrado de enfermería las manifestaciones de aquella concepción, apuntando para la necesidad de la actividad docente estar influenciada por la concepción de la enfermería/trabajo.

DESCRIPTORES: enfermería, trabajo

\footnotetext{
${ }^{1}$ Trabalho apresentado à disciplina: "A Saúde do Trabalhador no Contexto da Enfermagem", oferecida na cidade de Cascavel/PR como parte do Projeto de Mestrado Interinstitucional entre a Escola de Enfermagem de Ribeirão Preto da Universidade de São Paulo e a UNIOESTE/Cascavel; ${ }^{2}$ Enfermeiro, Professor do Colegiado do Curso de Enfermagem da UNIOESTE/Cascavel, e-mail: arluiz@zaz.com.br, Mestre em Enfermagem Fundamental da Escola de Enfermagem de Ribeirão Preto da Universidade de São Paulo, Centro Colaborador da OMS para o desenvolvimento da pesquisa em enfermagem
} 


\section{INTRODUÇÃO}

$\boldsymbol{C}_{\text {omo atividade no primeiro dia de aula na disciplina de }}$ Exercício da Enfermagem em um Curso de Graduação em Enfermagem, nos últimos três anos, tenho solicitado que os alunos escrevam entre outras coisas, qual é o seu entendimento de enfermagem. 0 que, predominantemente, tem aparecido é uma concepção da enfermagem enquanto ajuda, doação, vocação. Até que não haveria nenhum problema nisso, afinal, é compreensivel que $\mathrm{o}$ aluno, na primeira semana de aula, tenha tal entendimento desta prática, pois a sua elaboração teórica a respeito pode identificarse à do senso comum. Contudo, percebo que tal postura não é exclusiva de alunos recém chegados à área da enfermagem, nos parecendo que a ideologia presente na enfermagem brasileira, desde sua origem, é perpassada pelo entendimento do trabalho do enfermeiro como importante por estar permeado da uma atuação caritativa.

Num estudo feito com enfermeiras alemãs ${ }^{(1)}$ percebemos, nos discursos dos sujeitos da pesquisa, que esta enfermagem idealizada aparece como um dos elementos de satisfação profissional e de motivação para o trabalho. Como entender que os enfermeiros, mesmo após anos de exercício profissional, ainda guardem aquela visão idealizada da sua prática e se sintam satisfeitos, reconhecidos quando estão exercendo atividades de ajuda, de doação. 0 que tal entendimento pode acarretar ao enfrentamento dos problemas relacionados à saúde do trabalhador enfermeiro?

Desta maneira, proponho algumas reflexões preliminares acerca de uma possivel relação entre a concepção hegemônica de enfermagem enquanto vocação, serviço, compatível com o modelo vocacional/religioso e uma, também possível, dificuldade em se propor ações efetivas no campo da saúde do trabalhador enfermeiro; afinal, compreendo que ao tomar-se a enfermagem enquanto vocação, subtrai-se dela o seu caráter de um trabalho realizado em uma sociedade concreta, que tem carências, e na qual o profissional de enfermagem constitui-se em um trabalhador que vende a sua força de trabalho para garantir a sua existência.

Tenho como pressuposto o fato de que a concepção que se tem da enfermagem enquanto ajuda, vocação e não como trabalho, emperra as iniciativas de organização de seus trabalhadores na busca de condições apropriadas de trabalho, livre de riscos e menos penosa.

Percebo claramente os limites de tal pretensão. Desta forma, me limitarei a tecer considerações que indiquem a necessidade de se aprofundar os estudos, averiguando cientificamente a veracidade ou não de tal pressuposto.

\section{MÉTODOS}

Para tecer estas reflexões, fundamentando-na na literatura, pretendo tomar como orientação um resgate da história da enfermagem, situando o momento em que acredito estar alicerçada a atual concepção ainda hegemônica de enfermagem. Além disso, pretendo pontuar a iniciativa de mudança de concepção que acontece após a década de 80 , indicando a necessidade de um redirecionamento no entendimento da profissão entendendo-a como uma prática social, como trabalho. A pesquisa bibliográfica foi a fonte para a construção do texto.

Para ilustrar o que entendo por modelo vocacional/religioso e como isso ainda é presente nos discursos dos alunos, realizei coleta de dados com alunos do primeiro e do último ano de graduação em Enfermagem de 1999, solicitando-lhes que escrevessem o que significa enfermagem para eles, e porque estão fazendo o curso. Com a quarta série, solicitei ao professor, presente na sala, espaço para expor aos alunos a proposta e a colaboração em responder às perguntas, os da primeira responderam como atividade inicial da disciplina de Exercício da Enfermagem. Tive o cuidado de esclarecer que eles deveriam responder somente se desejassem e que seria resguardado o sigilo. Esclareci ainda que os dados destinavam-se a trabalho para publicação. Forneceram resposta, 37 alunos da primeira série e 23 alunos da quarta série.

Os dados colhidos foram reunidos e agrupados segundo a convergência de conteúdo, averiguando a ocorrência nas falas do modelo vocacional/religioso, uma vez que entendo que a concepção que se tem da enfermagem pode interferir na compreensão da problemática da saúde do trabalhador de enfermagem. Portanto, o núcleo central de convergência das falas foi a manifestação da concepção de enfermagem baseada no modelo vocacional/religioso. Penso que a perspectiva histórica e dialética seria coerente para este estudo, sendo o referencial adotado.

\section{ENFERMAGEM E O MODELO VOCACIONAL: A CONTEXTUALIZAÇÃO}

A história da enfermagem pode ser situada em antes, durante e depois da Idade Média. Antes deste período, esta prática era desenvolvida pelas mulheres na Sociedade Primitiva, pelos escravos, sacerdotes e também por mulheres na Sociedade Grega. Nos primitivos, a concepção de saúde/doença estava muito mais ligada ao sobrenatural, entendido como ação de espíritos; com os gregos, vai ligar-se a alterações nos humores, relacionando-se a causas objetivas e não apenas sobrenaturais ${ }^{(2)}$.

Até aquele momento, 0 ato de cuidar das pessoas estendiase às funções domésticas e alargava-se um pouco mais que isso apenas no cuidado às pessoas de posse, que tinham seus escravos para tal atividade. Apesar de ser exercida pelos escravos, não perdia 
sua característica de trabalho doméstico, com um fim em si mesmo.

Contudo, com o advento do cristianismo e o poderio da igreja, a prática da enfermagem sofreu profundas transformações. A concepção de saúde/doença é relacionada ao aspecto religioso onde a subalternidade do ser humano é total a um deus que é misericordioso, mas que também se manifesta como castigador. Assim, à saúde atribui-se um sentido de agrado a Deus e a doença passa a ser tomada como um castigo ${ }^{(2)}$.

Neste cenário, os executores do que poderia relacionar-se a um trabalho de enfermagem serão pessoas ligadas à Igreja ou pessoas leigas que tenham um desenvolvido espírito de caridade. Afinal, neste novo enfoque, aquele que cuidar dos doentes tem maiores chances de se aproximar de Deus através da caridade. Cuidar de pessoas doentes é como garantir junto a Deus a remissão dos pecados, pois como prega (va) a igreja, todos somos pecadores.

Este período imprimiu profundas marcas na história da humanidade e em função delas, até o momento atual, estão impressas em nossos valores, em nossas condutas cotidianas. Parece-me que estas marcas ainda perduram e se explicitam na concepção de enfermagem de alunos e enfermeiros. É claro que não com esta relação direta de ação e salvação da alma, mas os preceitos cristãos continuam muito arraigados em nosso fazer. Principalmente na sua forma idealista de conceber o mundo, em que se transcende para um mundo extraterreno as esperanças de viver uma vida plena, já que o mundo terreno é um lugar de padecimento e dor.

0 modelo religioso sofre algumas alterações na transição do Feudalismo para o Capitalismo, em função de que o primeiro já não é capaz de propiciar a organização do espaço hospitalar, que é modificado com este novo modo de produção. 0 hospital, de um lugar em que as pessoas iam apenas para esperar pela sua morte, transforma-se em um espaço de cura. "O modelo religioso de enfermagem emerge no mundo cristão, atravessa a Idade Média e vai se defrontar com o capitalismo na Inglaterra, no final do século XVIII, e com a ascensão da burguesia e sua instalação como classe social dominante, que dará o significado de arte ou vocação à prática de enfermagem, para tornar possível o treinamento de alguns agentes. Portanto, no capitalismo, o modelo religioso é substituído pelo vocacional"(3).

O modelo vocacional diferencia-se em função dos novos agentes que não serão mais somente os religiosos, mas também pessoas leigas. Contudo, não se trata de um modelo excludente do modelo religioso. Pelo contrário, muitos preceitos e ensinamentos religiosos persistirão na enfermagem moderna. A enfermagem moderna, como designamos a enfermagem que se organiza no século XIX com Florence Nightingale, reproduz muitas daquelas características. "Nightingale legitimou a hierarquia e a disciplina no trabalho de enfermagem, trazidas da sua alta classe social, da organização religiosa e militar, materializando as relações de dominação-subordinação, reproduzindo na enfermagem as relações de classe social. Introduziu o modelo vocacional ou a arte da enfermagem"(3).

Entendo que estas características, em função de se constituírem em construções históricas, persistem por todo o período capitalista apenas modificando sua forma de manifestação. Um outro fato é a origem da enfermagem, tanto no Brasil como na Inglaterra, que está ligada ao voluntarismo de guerra com Florence Nightingale e Ana Neri, ambas imprimindo tanto os valores militares como o espírito de serviço. "A ideologia da enfermagem desde sua origem, e, em particular, a de Ana Neri, para os brasileiros, significa: abnegação, obediência, dedicação. Isso marcou profundamente a profissão de enfermagem - 0 enfermeiro tem que ser alguém disciplinado e obediente. Alguém que não exerça a crítica social, porém console e socorra as vítimas da sociedade. Por essa razão, os enfermeiros enfrentam sérias dificuldades de ordem profissional, desde as longas jornadas de trabalho, baixos salários comparados aos de outros profissionais do mesmo nível, enfim, sua organização política é frágil e quase sem autonomia (...) $)^{(4)}$.

Contraditoriamente, é possível perceber no momento atual, que essa concepção de enfermagem enquanto vocação e do enfermeiro enquanto aquela pessoa que ajuda, que se doa, não é compatível com o modo como vivemos, em que o trabalhador enfermeiro precisa vender a sua força de trabalho para garantir a sua existência.

Os discursos dos enfermeiros no trabalho de Cunha, estavam carregados dos valores de ajuda, de dedicação, aos quais me referi como tendo sido construídos pelo modelo vocacional/ religioso. Esta autora faz uma reflexão pontual sobre estes valores e sua relação com o processo motivacional que, acredito, enriquece a afirmação de que o enfermeiro, muitas vezes, ainda se orienta por estes valores, mas que entendo seja preciso reorientá-los. Para ela: "A motivação caracterizada por sentimentos idealizados da profissão conflita-se com a realidade determinada pelo mercado de trabalho capitalista. Como ajudar os pacientes, ser solidária, prestar uma assistência integral, sentir-se útil, ser valorizada e recompensada em um contexto onde esses motivos e valores inexistem? Como atuar em condições desumanas, onde são priorizadas outras finalidades que não contemplam essa relação de ajuda, essa solidariedade e sentirem-se úteis e importantes? ${ }^{\prime(1)}$.

Embora as enfermeiras tenham esses valores construídos, sua atuação no mercado de trabalho é suficiente para fazer cair por terra, uma vez que neste não há espaço sequer para o ser humano doente, sendo este apenas uma peça na engrenagem do sistema de saúde, quanto mais para os trabalhadores. É neste sentido que é preciso não construir este mundo idealizado para o aluno, pontuando 
objetivamente os limites e as possibilidades do trabalhador enfermeiro.

Desta forma, vejo justificar-se o redirecionamento da nossa prática, seja através da assistência, do ensino e da pesquisa, permeando-a pelo entendimento da enfermagem enquanto trabalho. Penso que isto se traduz em uma forma objetiva de estar refletindo sobre a profissão, afastando a postura que até menos de duas décadas atrás era de total conformismo e aceitação de imposições, incluindo-se aí as condições de trabalho. "Este posicionamento não é freqüente porque as profissões da saúde (principalmente a medicina) são tomadas como desvinculadas do mundo do trabalho que obedece às leis sociais de necessidades, de carecimento, e esta desvinculação as coloca acima e além do mundo do trabalho, exaltando suas qualidades de 'verdade', de 'ciência', 'dedicação', de 'bem', 'sacerdócio' e de 'autonomia”'(5).

Nesse texto vemos a advertência para que a enfermagem deixe de ser assim considerada, para que se possa analisá-la em realidades concretas, apreendendo as contradições dinâmicas da prática e contribuindo com estratégias de mudança da realidade. Entendo que o enfrentamento das dificuldades dos trabalhadores da enfermagem, no que se refere às condições do trabalho que realizam, passa por esta tomada da mesma como um trabalho pois, só assim poderemos vislumbrar alguma possibilidade de transformação da nossa realidade.

Na década de 80, inicia-se no Brasil um movimento de redirecionamento e de tomada da enfermagem em uma nova perspectiva tendo sido elaborados diversos trabalhos com o novo enfoque. Uma das elaborações do entendimento de enfermagem que, me parece, se encaminha no sentido de esta prática em outra concepção, dá conta de que: "A enfermagem é uma ação, ou uma atividade realizada predominantemente por mulheres que precisam dela para reproduzir a sua própria existência e utilizam um saber advindo de outras ciências e de uma síntese produzida por ela própria para apreender o objeto da saúde naquilo que diz respeito ao seu campo específico (cuidado de enfermagem?) visualizando o produto final, atender às necessidades sociais, ou seja, a promoção da saúde, prevenção de doenças e a recuperação do indivíduo, ou o controle da população"(5).

Nesta definição, me parece explícito que a enfermagem está sendo tomada como um trabalho, uma vez que a sua ação engloba todos os momentos do processo de trabalho, os instrumentos, os meios e a finalidade. Quando defendemos a tomada da enfermagem como trabalho, precisamos afastar algumas definições que idealizam o conceito de trabalho, como por exemplo, o trazido para discussão na disciplina de saúde do trabalhador no contexto da enfermagem, colocando que: "Qualquer forma de trabalho humano; tem uma dignidade inalienável; é atividade de um ser racional e livre. Seu valor se mede pela perfeição com que é realizado. É um dever inelutável de todo homem, qualquer que seja a concepção religiosa que o inspira. Este dever é uma vocação do homem de completar e prolongar pelo trabalho a obra criadora de Deus e a vocação de realizar a sua própria plenitude, pelo desenvolvimento de suas energias físicas e espirituais. É penoso e esta pena dá-lhe o valor de purificação e redenção. É um direito reconhecido pelas DUDH”(6).

Diferentemente de tal conceito que, carregado do entendimento de um homem idealizado, apartado de sua história e do trabalho como aquela tarefa de penúria que aproxima-nos de Deus, característica do período cristão, é preciso compreender o trabalho como a atividade humana que possibilita ao homem se produzir, se fazer homem. Pelo trabalho, "o ser humano se contrapõe e se afirma como sujeito num movimento e ação teleológica sobre a realidade objetiva. Modificando a realidade que o circunda, modifica-se a si mesmo. Produz objetos e, paralelamente, altera sua própria maneira de estar na realidade objetiva e de percebê-la. E - o que é fundamental - faz a sua própria história. Toda a chamada história mundial assegura Marx - não é senão a produção do homem pelo trabalho humano"(7).

Feitos tais esclarecimentos sobre como entendo a enfermagem e o trabalho, inicio a discussão dos dados colhidos relacionando-os com estes conceitos explicitados.

\section{ANÁLISE DOS DADOS ORIENTADA PELA COMPREENSÃO DA ENFERMAGEM SOB O MODELO VOCACIONAL/RELIGIOSO}

Dos alunos do primeiro ano de enfermagem de 1999, 37 responderam às questões, sendo que pude identificar traços do modelo vocacional/religioso em 18 falas, as quais passo a transcrever a seguir.

(...) como enfermeiro, vou poder ajudar aqueles que precisam de auxílio. (...)

é um dom de trazer alívio para aqueles que sofrem (...)

É a parte 'social' que tanto precisa um hospital

(...) é um meio de ajudar cada pessoa (...)

(...) que poderei ser solidária com as pessoas e assistir a comunidade de maneira gratificante.

(...) acho muito bonita pelo fato de ajudar as pessoas. (...)

(...) ajudar as pessoas tanto prevenindo doenças como ajudando a curálas.(...)

(...) somos treinados para que através do nosso trabalho, possamos ajudar os outros.

Enfermagem = compreensão, auxílio ao próximo, paciência, proporcionar vida, dar bem-estar, solidariedade. É uma profissão que pode proporcionar satisfação pessoal. 
(...) sendo enfermeira posso ajudar as pessoas doentes, pois ser enfermeira é uma profissão que se caracteriza em ajudar quem necessita.

(...) é ajudar no que for preciso, fazendo com que o doente se sinta bem.

(...) exige muita paciência e qualificação por se tratar de 'vidas' que necessitam de cuidados e ajuda.

Talvez seja uma das profissões que mais ajudam o ser humano e é talvez por um desses motivos que escolhi o curso.

(...) consiste em cuidar e ajudar as pessoas quando estão doentes ou sadias.(...)

(...) se volta a ajudar pessoas, dando um bom tratamento quando estas se encontram com problemas (...)

(...) aptidões que um profissional da área precisa ter (...) paciência, facilidade de relacionamento com pessoas e gostar de trabalhar em hospitais, (...) é para mim um curso que ajuda pessoas (...)

(...) uma das formas pelas quais vou ajudar, orientar, confortar... pessoas que precisam de cuidados.

(...) é inteiramente tratar e dar apoio as pessoas que estão precisando de ajuda.

(...). Ter muita compreensão, carinho e respeito com o ser humano. (...)

O conteúdo das falas destes alunos, ao ingressarem na Universidade, nos permite afirmar que um percentual elevado deles $(48,6 \%)$ atribui à enfermagem as características de ajuda, de valorização do contato com o ser humano como forma de satisfazer uma necessidade pessoal de ajudar os outros. Estes traços coincidem, em muitos momentos, com aqueles valores inculcados pelo modelo religioso/vocacional, sendo a ajuda uma das formas de alcançar a gratificação, seja no mundo terreno sentindo-se satisfeitos com o trabalho ou implicitamente a recompensa que pode ser conseguida em uma vida posterior por estar ajudando.

Por outro lado, observei no restante dos respondentes, alguns apontamentos indicando a tomada da enfermagem em outra direção. Em alguns momentos, esse redirecionamento apenas enseja uma escolha profissional, ligada ao fato de ser ainda uma profissão com amplo campo de trabalho, como se pode ver nestas falas.

(...) e também uma forma de garantir um emprego numa profissão que ainda não está saturada.

(...) a enfermagem também é um curso muito bom, com amplo campo de trabalho. (...)

(...) é um curso interessante, tem muito campo de trabalho, (...)

(...) Posso garantir que não foi uma tarefa fácil escolher o curso que vai me garantir a sobrevivência para o resto de minha vida.

(...) um curso reconhecido nacionalmente e com campo de trabalho (...)

(...) influências das pessoas que me disseram ter maior campo de trabalho(...)

Os demais respondentes refletem sobre a enfermagem e sua escolha, em função de que gostariam de fazer um outro curso na área da saúde, principalmente medicina, mas que em virtude da não aprovação no vestibular acabaram optando pela enfermagem, por ser o que mais se aproximava da área da saúde. Esta questão com certeza é bem mais complexa e não mereceria ser apenas citada, mas dados os limites deste trabalho, acredito não ser possivel discutir os determinantes da priorização da medicina como o curso mais procurado, nem os possíveis desdobramentos que isso possa trazer no exercício do trabalhador enfermeiro que não entra no curso de graduação com uma predisposição para cursar a enfermagem.

Os dados colhidos com os alunos do quarto ano do curso de enfermagem de 1999, não se apresentaram com as mesmas características dos colhidos com os alunos do primeiro ano. $\mathrm{Na}$ realidade, o resultado apresentou-se bastante inverso. 0 que encontrei predominante nas respostas daqueles alunos foi uma concepção mais elaborada da enfermagem, uma visão da enfermagem como profissão que faz parte da área da saúde e que desenvolve atividades de assistência, (cuidado direto?), prevenção, orientação e administração, como podemos ver nestes fragmentos de fala.

(...) é uma profissão que muitas vezes é confundida com dom. (...)

(...) é a profissão que tem por objetivo administrar a assistência aos pacientes, fazer educação em saúde para prevenção, e tem como objeto de estudo o cuidado ao paciente (...)

(...) área da saúde que presta assistência ao paciente, direta ou indiretamente. Diretamente através de cuidados, procedimentos e técnicas visando a recuperação da saúde, fazendo educação em saúde, prevenindo doenças e indiretamente, coordenando a equipe de enfermagem e administrando a unidade.(...)

(...) Enfermagem para mim é uma profissão como qualquer outra, mas um tanto estigmatizada e que fica escondida, muitas vezes, atrás do médico. A enfermagem se destina ao cuidar, prestar assistência, orientar. (...)

(...) área da equipe de saúde que está voltada aos cuidados com pacientes e prevenção, por isso atendendo nos 3 setores da saúde $\left(1^{\circ}, 2^{\circ}, 3^{\circ}\right) .(.$.

(...) profissão que se dedica tanto ao cuidado direto da pessoa como a prevenção de doenças, orientação referente a todos os aspectos que envolvem o ser humano desde a saúde coletiva o planejamento familiar, o fator psicológico de cada indivíduo, enfim o tratamento do ser humano como um todo. (...)

(...) profissão onde se presta assistência a cliente/paciente e além da assistência se administra hospital/posto e outros. (...)

(...) uma profissão que assiste o paciente, tanto na prevenção quanto no tratamento da doença

(...) profissão que presta assistência ao paciente, tanto internado quanto domiciliar. (...)

(...) profissão que tem por objetivo a assistência ao paciente, seja ela prestada direta ou indiretamente dentro ou fora de qualquer instituição. (...)

(...) profissão que eu gostei de conhecê-la e me adaptei as suas exigências.

(...)

(...) profissão que tem como objetivo a assistência humanizada do indivíduo 
como um todo, claro que dentro das limitações impostas pelo meio onde o enfermeiro se insere. É uma profissão que deve abranger a área de prevenção, curativa, de educação e pesquisa, voltada para a melhoria do quadro saúde-doença. (...)

Nestas falas, percebo que o aluno que está no quarto ano de enfermagem elaborou entendimento bastante diferenciado do que está no primeiro. Em seus discursos, a enfermagem deixa de ser remetida a uma atividade de ajuda, de dedicação, para ser uma profissão, e como percebemos, já apontam para os limites da profissão dentro do seu meio. Porém, nosso pressuposto era de que 0 aluno do quarto ano, também, manifestasse aquela visão idealizada, uma vez que é a corrente na enfermagem. Questionamos quais os motivos de termos encontrado tal inversão.

Numa primeira reflexão poderíamos atribuir tal transformação ao fato de que esta turma de alunos constitui-se na primeira turma a ser formada tendo como orientação o novo Currículo Mínimo de enfermagem estabelecido pelo Parecer 314/94 do MEC. Assim, arriscaria dizer, que este novo enfoque, pode estar sendo construído pela atual disposição das disciplinas e pelo incremento de disciplinas na área de Administração no segundo, terceiro e quarto anos como, também, as disciplinas instrumentalizadoras da pesquisa já no terceiro ano, e continuando no quarto ano (Projeto de Conclusão de Curso I e II). Além dessas, muitas outras alterações nas disciplinas e no tratamento dos conteúdos foram implementadas e isso com certeza, redireciona o trabalhador que está sendo formado.

Contudo, são apenas apontamentos e que não podem ser tomados como totalmente seguros, uma vez que uma análise da nova grade curricular em conjunto com todas as disciplinas ainda não foi implementada. Porém, acredito que estes dados já apontam indícios de que diferenças se construíram. E uma das causas pode ser a mudança do Currículo Mínimo. Por outro lado, as mudanças nas estruturas formais do ensino estão impregnadas pelo conjunto das transformações que acontecem em todos os espaços sociais. Nesse sentido, pergunto-me quais alterações na sociedade estão acontecendo que determinam uma outra percepção da enfermagem? Penso que os limites desse trabalho e a natureza dos dados colhidos não me permitem, nesse momento, aprofundar essa discussão, apontando a necessidade de uma pesquisa específica para esclarecer essa indagação.

Pude perceber nítidos traços daquela concepção vocacional religiosa da enfermagem apenas em três falas dos alunos, como se pode ver:

Estou cursando enfermagem, pois gosto de lidar com pessoas e ajudar a suprir as necessidades básicas biopsicosociais das pessoas que precisam de ajuda e orientação.

Para mim enfermagem é uma arte, pois cuidar do bem estar do ser humano requer muito amor, muita dedicação e muita técnica.
(...) é uma profissão linda, quando desenvolvida com responsabilidade, competência, amor (...).

Desta maneira, acredito poder afirmar que a maioria dos alunos do quarto ano, não tem como pressuposto para o seu trabalho somente a questão da ajuda. Acredito que isso seja fruto de um conjunto de determinações, podendo ser incluído ainda o movimento de crítica da profissão que se iniciou na década de 80 e que, com certeza, contribuiu para reflexões e mudanças na prática docente e também na assistencial. É claro que muito ainda há por ser feito.

Gostaria de reforçar a necessidade de intensificar a atitude docente tomando a enfermagem como uma prática complexa, exercida em uma sociedade concreta, onde o trabalhador não é muito mais que um artigo descartável como os demais meios e instrumentos de trabalho. Entendo que a escola por si não possa ser responsabilizada pelas dificuldades do trabalhador no mercado de trabalho como também pelas transformações na realidade. Porém, da mesma forma que repassar uma visão idealizada do enfermeiro pode contribuir para aumentar sua dificuldade de inserção no trabalho e sua luta por melhores condições no mesmo, uma nova postura concebendo o trabalho da enfermagem com todos os seus limites e potencialidades, pode contribuir, grandemente, para transformar as relações de trabalho na enfermagem e na saúde.

\section{CONSIDERAÇÕES FINAIS}

A pretensão neste ensaio reflexivo foi apontar algumas questões que me parecem importantes quando nos propomos a discutir a saúde do trabalhador enfermeiro e dos demais trabalhadores da equipe. Pretendia levantar a necessidade de direcionar 0 entendimento, enquanto docentes em enfermagem, para a enfermagem como um trabalho, pois acredito que isso reconstrói a postura frente a reivindicações por melhores condições de trabalho para a enfermagem.

Além desse aspecto específico de saúde no trabalho, acredito que, ao nos percebermos trabalhadores (nós enfermeiros), muitos dos conflitos entre nós e a equipe de enfermagem (técnicos, auxiliares, atendentes) são redimensionados. Afinal passamos a coexistir em igualdade de condições. 0 que nos aproximaria dos demais agentes.

Precisamos definir a que classe pertencemos. Somos da classe trabalhadora? Nos assumimos como tal, ou somos apenas intermediários entre uma elite e os demais trabalhadores? Acredito que esta última posição seja a dominante até o momento. Aí podem estar residindo alguns de nossos "conflitos existenciais". Sua superação, passa pela compreensão do enfermeiro como um trabalhador. 


\section{REFERÊNCIAS BIBLIOGRÁFICAS}

1. Cunha $\mathrm{K}$ de $\mathrm{C}$. $\mathrm{O}$ contexto e o processo motivacional vivenciado por enfermeiras. [tese]. São Paulo: Escola de Enfermagem/USP; 1994.

2. Silva G. Enfermagem profissional análise crítica. 2.ed. São Paulo (SP): Cortez; 1989.

3. Almeida MCP, Rocha JSY. O saber da enfermagem e sua dimensão prática. 2.ed. Paulo (SP): Cortez; 1989.

4. Germano RM. Educação e ideologia da enfermagem no Brasil. 3. ed. São Paulo (SP): Cortez; 1993.
5. Almeida MCP, Rocha SMM. Considerações sobre a enfermagem enquanto trabalho. In: Almeida MCP, Rocha SMM, organizadoras. 0 trabalho da enfermagem. São Paulo (SP): Cortez; 1997. p.15-26.

6. BRASIL/MEC, 1975. Trabalho Cascavel. Disciplina: A Saúde do Trabalhador no Contexto da Enfermagem, 1999.

7. Frigotto G. Educação, crise do trabalho assalariado e do desenvolvimento: teorias em conflito. In: Frigotto $G$, organizador. Educação e crise do trabalho: perspectivas de final de século. Petrópolis (RJ): Vozes; 1998. p. 25-54. 